\title{
Multi-Analytical Approach for Asbestos Minerals and Their Non-Asbestiform Analogues: Inferences from Host Rock Textural Constraints
}

\author{
Gaia Maria Militello ${ }^{1, *(\mathbb{C}}$, Andrea Bloise $\left.{ }^{2} \mathbb{(}\right)$, Laura Gaggero ${ }^{1}\left(\mathbb{D}\right.$, Gabriele Lanzafame $^{3}$ and \\ Rosalda Punturo ${ }^{4}$ \\ 1 Department of Earth, Environment and Life Sciences - DISTAV, University of Genoa, Corso Europa 26, \\ I-16132 Genoa, Italy; gaggero@dipteris.unige.it \\ 2 Department of Biology, Ecology and Earth Sciences, University of Calabria, Via Pietro Bucci, I-87036 Rende, \\ CS, Italy; andrea.bloise@unical.it \\ 3 Elettra-Sincrotrone Trieste S.C.p.A., I-34149 Trieste, Italy; gabriele.lanzafame@elettra.eu \\ 4 Department of Biological, Geological and Environmental Sciences, University of Catania, Corso Italia 55, \\ I-95129 Catania, CT, Italy; punturo@unict.it \\ * Correspondence: gaiamaria.militello@edu.unige.it; Tel.: +39-010-3538301
}

Received: 28 February 2019; Accepted: 3 May 2019; Published: 10 May 2019

\begin{abstract}
Asbestos is a hazardous mineral, as well as a common and well-known issue worldwide. However, amphiboles equal in composition but not in morphology, as well as the fibrous antigorite and lizardite, are not classified as asbestos even if more common than other forms of the mineral. Still, their potential hazardous properties requires further exploration. The proposed multi-instrumental approach focuses on the influence of textural constraints on the subsequent origin of asbestiform products in massive rock. This aspect has a significant effect on diagnostic policies addressing environmental monitoring and the clinical perspective. Concerning minerals that are chemically and geometrically (length $>5 \mu \mathrm{m}$, width $<3 \mu \mathrm{m}$ and length:diameter $>3: 1$ ) but not morphologically analogous to regulated asbestos, the debate about their potential hazardous properties is open and ongoing. Therefore, a selection of various lithotypes featuring the challenging identification of fibrous phases with critical counting dimensions was investigated; this selection consisted of two serpentinites, one metabasalt and one pyroxenite. The analytical protocol included optical microscopy $(\mathrm{OM})$, scanning and transmission electron microscopy combined with energy dispersive spectrometry (SEM/EDS; TEM/EDS), micro-Raman spectroscopy and synchrotron radiation X-ray microtomography (SR X-ray $\mu \mathrm{CT}$ ). The latter is an original non-destructive approach that allows the observation of the fiber arrangement in a three-dimensional space, avoiding morphological influence as a result of comminution.
\end{abstract}

Keywords: texture; naturally occurring asbestos; morphology; cleavage fragments; asbestiform and fibrous minerals; environmental monitoring

\section{Introduction}

The term asbestos is a generic term comprising some natural minerals represented by hydrated silicates that are easily separable in thin, flexible fibers, resistant to traction and heat and almost chemically inert. The minerals defined as asbestos include the asbestiform varieties of minerals belonging to the amphibole group, such as riebeckite (under the commercial name of crocidolite), cummingtonite-grunerite series (under the commercial name of amosite), tremolite, actinolite and anthophyllite, as well as minerals belonging to the serpentine group (chrysotile). In detail, the term asbestiform refers to a specific type of mineral fibrosity, with high tensile strength and/or flexibility [1]. 
Therefore, in national and international normative definitions worldwide, minerals defined as asbestos include only fibrous and asbestiform varieties of the serpentine and amphibole groups, i.e., only those varieties that possess high tensile strength or flexibility. Meanwhile, the prismatic varieties of amphiboles, despite the fact that they have the same chemical composition, are not classified as asbestos. In terms of geometrical ratios, they would be classified as fibers (length $>5$ $\mu \mathrm{m}$, diameter $<3 \mu \mathrm{m}$ and length/diameter ratio $>3: 1$ ), but they are not asbestiform minerals; however, a clear relationship between their morphology and toxicity is still undemonstrated.

Nevertheless, even these geometric relationships are not univocally constrained; in fact, different counting criteria have been adopted for the assessment of asbestos risk and its identification [2]. Furthermore, it is difficult to discriminate the asbestos amphibole from prismatic crystals or cleavage fragments, especially if they are associated with one another.

Although it has been banned since 1992 in Italy and in many other countries worldwide [3], the management of asbestos is ruled by quite obsolete legislation and does not take into account many parameters for correct phase classification. This leads to problems of compatibility and reproducibility between different laboratories. Another concern is the classification of non-asbestos classified fibers [4] whose potential hazard is not fully investigated, such as prismatic and acicular habits or cleavage fragments of amphiboles and other elongated mineral particles (EMP) that are even more common [5]. Research and debate are in progress about the composition and morphology of the various types of asbestos and the related fibrous minerals not classified as asbestos, such as erionite and fibrous antigorite [6,7], which are similar in morphology to the polymorph chrysotile of asbestos and not always distinguishable. This morphology is regulated as asbestos only in the New Caledonia legislations [8]. As a consequence, quantitative determinations can yield high variance even for similar conditions or naturally occurring asbestos (NOA) types [9,10], preventing a risk assessment based on univocal data.

Therefore, the distinction between asbestos and non-asbestiform analogues is flawed from both a scientific and a regulatory standpoint [11-13]. Moreover, the habit at the macroscale does not always correspond to that observed at the microscale (i.e., not repeated with fractal geometries) [14]. In most laboratories phase-contrast light microscopy (PCM) or transmission electron microscopy with energy-dispersive X-ray analysis and selected-area electron diffraction (TEM/EDS/SAED) are traditionally used to characterize and evaluate the fiber concentrations in NOA aggregates $[15,16]$. TEM/EDS/SAED with a higher magnification and the possibility of mineral phase speciation allows the identification of chemical and crystallographic structure [17,18]. For example, in many works, the diameter of the chrysotile as well as those of amphiboles fibers were more accurately measured by TEM micrographs [18]. However, when the elongated particles are very thin, even with TEM it may not be possible to adequately differentiate asbestiform fibers from prismatic crystals or cleavage fragments. Moreover, in recent years other analytical techniques (e.g., $\mu$-Raman, thermal analysis) have been able to better discriminate and quantify the asbestos mineral occurrence in rocks [19-21].

In this context, the object of this work is to compare, at different observation scales, by a multi-instrumental approach, e.g., [22], the morphological features and the influence of textural constraints in massive samples which determine the origin of fibrous and asbestiform or fibrous but not asbestiform products, or rather the EMP of amphibole and serpentine groups. These EMP therefore comprise cleavage fragments of minerals belonging by composition, but not necessarily by morphology, to the group of asbestos minerals.

Moreover, a new application of the synchrotron radiation X-ray microtomography (SR X-ray $\mu \mathrm{CT}$ ), not yet used before for asbestos detection, was adopted. This semi-destructive technique was chosen because it can help to better observe the arrangement of the fibers in the three dimensions and facilitate the comparative description of cleavage fragments. Specially, if subjected to comminution, the preliminary step for the preparation of the samples according to the methods is regulated by law $[1,23]$. In order to understand whether the counting dimensions (length $>5 \mu \mathrm{m}$, diameter $<3 \mu \mathrm{m}$, length: diameter $>3: 1$ ) have a bearing on the quantification, as a result of the comminution from an 
acicular or a fibrous crystal, five samples of metamorphic lithotypes containing serpentine and/or amphibole asbestos were addressed in the following multi-analytical investigations.

\section{Materials and Methods}

\section{Dataset and Geological Provenance of Samples}

The dataset is represented by two serpentinites (S1 and S2), one metabasalt (S3) and one metasomatized pyroxenite (S4).

Sample S1 (Piedmont, Italy) is a serpentinized peridotite cut by a fibrous/acicular lizardite-filled vein (Figure 1a). Sample S2 (Aosta Valley, Italy) is a serpentinite cut by a vein of dolomite, acicular and more or less fibrous tremolite and rare chrysotile (Figure 1b). Sample S3 (Piedmont, Italy) is a metabasalt with an intersertal texture where skeletal albite and acicular/prismatic and occasionally fibrous actinolite occur. The rock is cut by a plagiogranite vein formed mainly by primary plagioclase, secondary calcite and actinolite (Figure 1c). Sample S4 (Gauteng, South Africa) is a pyroxenite cut by millimeter-thick veins of the fibrous/acicular form of the actinolite-tremolite series associated with talc; the protolith is a metasomatized metagranitoid (Figure 1d).

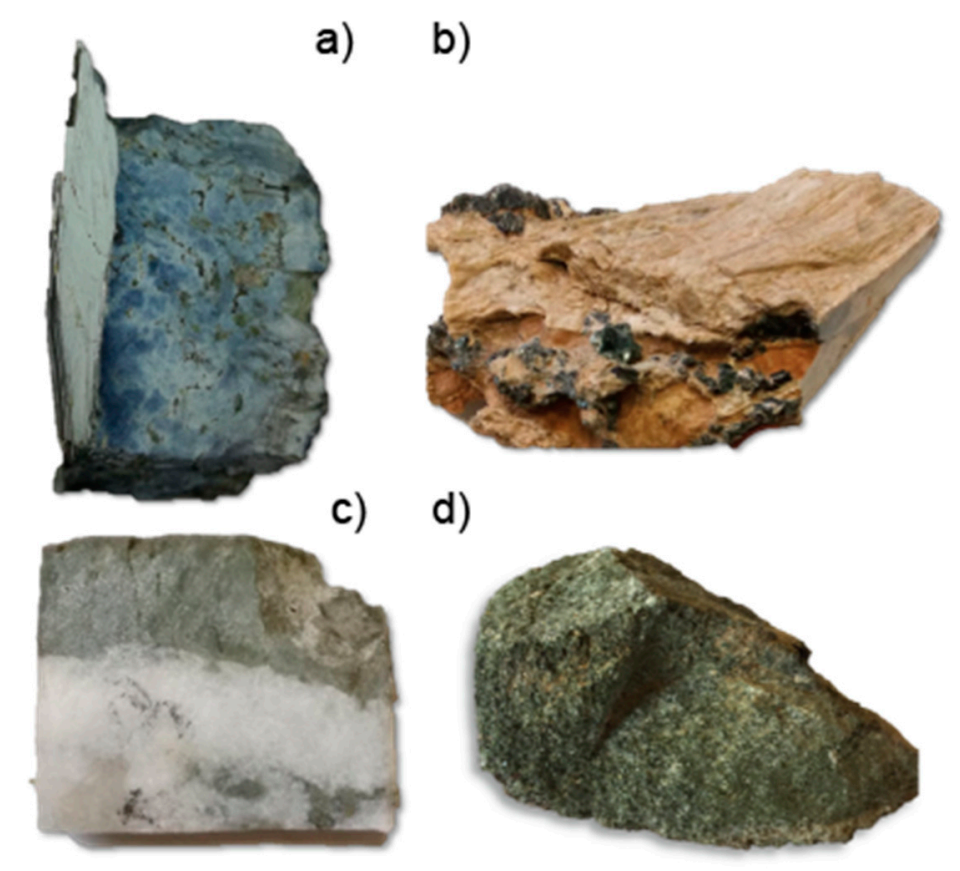

Figure 1. Close up photographs of the analyzed samples: (a) serpentinized peridotite; (b) serpentinite with a tremolite vein; (c) metabasalt with a plagiogranite vein; (d) pyroxenite cut by a talc and tremolite-filled vein.

These samples were chosen as lithotypes with different petrological evolutions. They were also chosen because the characterization and identification of the fibrous phases is challenging. Samples were analyzed by optical microscopy (OM) (ZEISS, Thornwood, NY, USA), scanning and transmission electron microscopy combined with energy dispersive spectrometry (SEM/EDS and TEM/EDS) (SEM/EDS: TESCAN, Brno, Czech Republic; TEM/EDS: Jeol, Tokyo, Japan), $\mu$-Raman (HORIBA, Longjumeau, France) and synchrotron radiation X-ray microtomography (SR X-ray $\mu \mathrm{CT}$ ) (Hamamatsu, Hamamatsu City, Japan). For the latter technique, S1 underwent microtomographic analysis but was subsequently discarded due to the high and almost equal density of the mineralogical phases, and the consequent low-density contrast and lack of voids or fractures, which determined an almost total absorption of the X-rays and prevented the collection of significant information. 


\section{Analytical Methods}

Many of the naturally occurring asbestos (NOA) types which are either fibrous or asbestiform and therefore regulated, show very similar optical characteristics. For this reason, their recognition requires in most cases the combined use of various analytical techniques, such as optical microscopy $(\mathrm{OM})$, scanning electron microscopy with microanalysis (SEM/EDS), transmission electron microscopy with microanalysis (TEM/EDS), Fourier transform infrared spectroscopy, Raman spectroscopy and $X$-ray powders diffractometry. In our work we also added the use of an unconventional technique for the detection and characterization of NOA, namely synchrotron radiation microtomography $(\mathrm{SR}-\mu \mathrm{CT})$.

Optical microscopy $(\mathrm{OM})$ is the fastest of these techniques for the recognition of different phases, and possibly of their morphology. Moreover, it provides an excellent indication of microstructural relationships within a rock. Most determinations were carried out with a Zeiss Axiolab Microscope with Polarized Light, located at the Department of Biological, Geological and Environmental Sciences of the University of Catania, Italy.

Scanning electron microscopy (SEM) makes possible morphological investigations under higher magnifications (up to 10,000X) with coupled in situ microanalysis to obtain compositional information. Sample preparation and qualitative determination were accomplished at the Electron Microscopy Laboratory of the Earth Environment and Life Sciences Department (DISTAV), University of Genoa, Italy, using a scanning electron microscope (TESCAN 3 XML) (TESCAN, Brno, Czech Republic). The work parameters were: $2000 \times$ of magnification (Mag) and $20 \mathrm{kV}$ of accelerating voltage (HV). The elemental analysis of the minerals was carried out by energy dispersive X-ray spectroscopy (Oxford Instruments, AZtec 2.4) (TESCAN, Brno, Czech Republic). According with dimensions and chemical composition, minerals were detected and considered as asbestos fibers. Other EMP were analyzed to characterize them.

Micro-Raman spectroscopy allows the rapid identification of fibrous phases, providing information on the different vibrational modes of molecules. In particular, this technique has the advantage of being able to use the sample as is by positioning it on the stage of the microscope, or the same thin sections prepared for the observations in optical microscopy can be used. Micro-Raman scattering measurements were conducted at the Earth Environment and Life Sciences Department (DISTAV), University of Genoa, Italy, with a Horiba Jobin-Yvon Explora_Plus single monochromator spectrometer (HORIBA, Longjumeau, France) (with a grating of 2400 groove/mm) equipped with an Olympus BX41 microscope (HORIBA, Longjumeau, France). Raman spectra were excited by the $532 \mathrm{~nm}$ line. The spectrometer was calibrated to the silicon Raman peak at $520.5 \mathrm{~cm}^{-1}$. The spectral resolution was $\sim 2 \mathrm{~cm}^{-1}$ and the instrumental accuracy in determining the peak positions was $\sim 0.56 \mathrm{~cm}^{-1}$. Raman spectra were collected in the spectral ranges of $100-1100 \mathrm{~cm}^{-1}$ and $3000-3800 \mathrm{~cm}^{-1}$ for $15 \mathrm{~s}$, averaging over 10 accumulations. In this work, this technique was used for the serpentine mineral identification of sample S1. Three analysis points were performed on three different parts of the sample: in the host rock, in the vein/rock interface and finally in the vein.

The transmission electron microscopy (TEM) associated with the microanalysis system implements the previous techniques, reaching atomic resolutions that allow the recognition of the different minerals of the serpentine sample and of all types of amphiboles. However, the technique addresses powders and therefore does not preserve the morphological and microstructural information of the sample. Finally, the preparation of the sample requires expert handling. Transmission electron microscopy (TEM), installed at the Department of Biology, Ecology and Earth Sciences, University of Calabria (Cosenza, Italy), was performed using a Jeol JEM 1400 Plus (Tokyo, Japan) working at $120 \mathrm{kV}$, equipped with a double tilt holder to check the morphology of the samples and to obtain structural data by selected area electron diffraction (SAED). Moreover, energy dispersive X-ray spectrometry (EDS) performed using the Jeol allowed us to obtain analytical electron microanalyses (AEM). In order to discriminate the asbestos fibers chemically, a three-point analysis were carried out on each single fiber. For TEM investigations, a small aliquot of the sample was ground using an agate pestle and mortar in 
isopropyl alcohol and then sonicated; this powder was then deposited onto a copper mesh grid coated with $200 \AA$ A carbon film. With TEM/EDS, only fibrous morphologies were investigated.

\section{Synchrotron Radiation Microtomography (SR- $\mu \mathrm{CT})$ Measurements}

The three-dimensional study of three samples was performed at the SYRMEP beamline of the Elettra synchrotron laboratory (Trieste, Italy) by using high-resolution SR- $\mu \mathrm{CT}$ in phase-contrast mode [24].

The selected samples were cut in the form of a parallelepiped with a square base with dimensions of $2 \times 0.5 \mathrm{~cm}^{2}$ and illuminated by a polychromatic X-ray beam (white beam configuration) in transmission geometry. The contribution of low energies in the beam spectrum was suppressed by applying $1 \mathrm{~mm}$ $\mathrm{Si}+1 \mathrm{~mm}$ Al filters. The SR- $\mu \mathrm{CT}$ was performed with a fixed sample-to-detector distance of $200 \mathrm{~mm}$ and collected, for each sample, 1800 projections over a total scan angle of $180^{\circ}$ with an exposure time per projection of $2 \mathrm{~s}$. The employed detector was a 16 bit, air-cooled, sCMOS camera (Hamamatsu C11440 22C) (Hamamatsu, Hamamatsu City, Japan) with a $2048 \times 2048$ pixel chip and an effective pixel size set at $1.95^{2} \mu \mathrm{m}^{2}$, yielding a maximum field of view of ca. $3.2^{2} \mathrm{~mm}^{2}$. Since the lateral size of the samples was larger than the field of view of the detector, microtomographic scans were acquired in region-of-interest mode [25].

The 2D tomographic slices were reconstructed using the Syrmep Tomo Project (STP) house software suite [26], which allowed the application of different filters in order to reduce ring artefacts caused by detector inhomogeneity [27]. A single-distance phase-retrieval algorithm [28] based on the transport of intensity equation (TIE) was applied to the sample projections to improve the consistency of the morphological analysis. Combining phase-retrieval and filtered back-projection algorithms [29] allowed obtaining the 3D distribution of the complex refraction index of the imaged samples. This process reduces the edge-enhancement effect at sample borders, at the same time preserving the morphology of the smallest features.

The obtained 3D volumes were then segmented by manual thresholding. Three-dimensional renderings were obtained by VGStudio Max 2.2 software (Volume Graphics, Heidelberg, Germany).

\section{Results}

Prior to SR X-ray $\mu \mathrm{CT}$, mineralogical and microtextural observations were carried out at the microscale, followed by a compositional and morphological analysis of polished thin sections. Microtextural sites with higher concentrations in fibrous and/or prismatic-acicular varieties of NOA were selected to be addressed to the microtomography runs.

\subsection{Microtexural Observations}

\subsubsection{Sample S1: Serpentinized Peridotite}

Since serpentine minerals have very similar optical properties and frequently have sub-microscopic intergrowths, especially when they have a fibrous habit (e.g., in veins) [30], it was necessary to begin the characterization of this sample with a preliminary analysis determined by $\mu$-Raman. From the point analyses compared with the spectra in [31], it emerged that the vein (analysis spot 1 shown in Figure $2 b$ ) is represented by lizardite (Figure $2 a, b$ ) and that the interface between the vein and the host rock (analysis spot 2 in Figure 2d) is filled with chrysotile (Figure 2c,d).

The identification of the polymorphs was carried out by comparing the low- and high-wavenumber regions. In detail, the region of low-wavenumber $\left(150-1000 \mathrm{~cm}^{-1}\right)$ corresponds to the vibrational mode of the crystal lattice and the vibrations of $\mathrm{Si}-\mathrm{O}_{4}$; contrariwise, in the high-wavenumber region the stretching vibration behavior of the $\mathrm{OH}$ group $\left(3500-3800 \mathrm{~cm}^{-1}\right)$ is displayed. The low-wavenumber region is sometimes ambiguous because a little modification of the chemical composition could modify the intensity of the peak as well as the vibrational wave number and its intensity. Therefore, for the 
distinction of the serpentine polymorphs it is absolutely fundamental for the visualization of the vibration of the $\mathrm{OH}$ group, which is very sensitive to the variation of the geometry of the layers [31].

From the literature, the peaks at 230, 390 and $690 \mathrm{~cm}^{-1}$ are similar in both chrysotile and lizardite but are slightly shifted in antigorite. In particular, the peak at $230 \mathrm{~cm}^{-1}$ is associated with the $\mathrm{O}-\mathrm{H}-\mathrm{O}$ vibration in which the $\mathrm{O}$ is that not bound to the tetrahedra $\mathrm{SiO}_{4}$ and the $\mathrm{H}$ is the hydrogen outside the $\mathrm{OH}$ group [31]. The peak at $390 \mathrm{~cm}^{-1}$ represents the mode of $\mathrm{SiO}_{4} v_{5}$ (e) and the peak at $692 \mathrm{~cm}^{-1}$ corresponds to the symmetrical $\mathrm{Si}-\mathrm{O}_{\mathrm{b}}-\mathrm{Si}$ stretching.

In our case, the lizardite (Figure 2a) has very intense peaks at 690, 384 and $231 \mathrm{~cm}^{-1}$; however, the peaks at 3682 and $3704 \mathrm{~cm}^{-1}$ are discriminating (Figure $2 \mathrm{~b}$ ).

The chrysotile (Figure 2c) shows peaks at 230, 385 and $690 \mathrm{~cm}^{-1}$, while the $\mathrm{OH}$ group shows the main peak at $3697 \mathrm{~cm}^{-1}$ (Figure 2d) with a small hump of lower intensity.
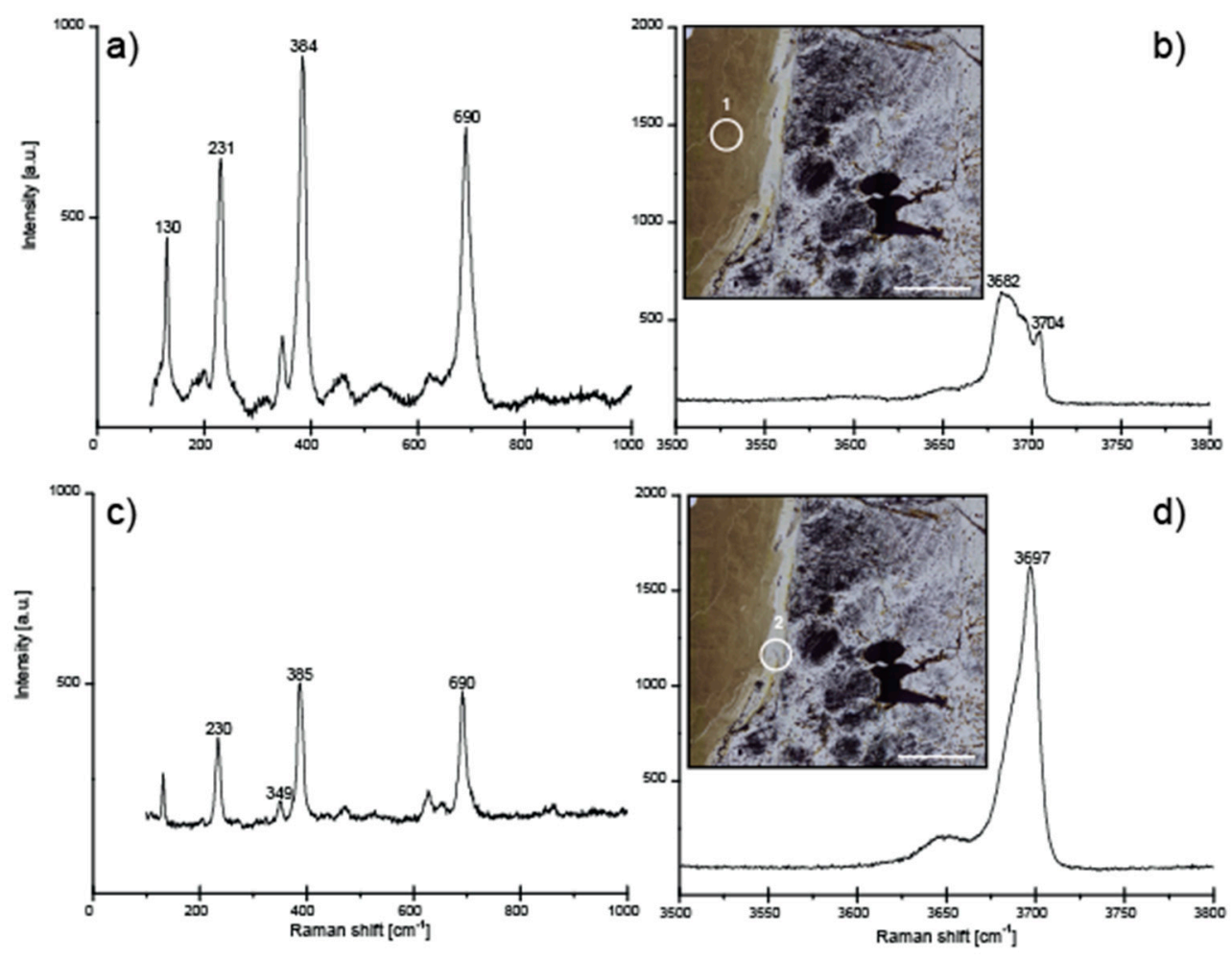

Figure 2. Raman spectra in the low- and high-wavenumber regions of lizardite ((a,b), respectively) and chrysotile ((c,d), respectively). Photomicrographs show the positions of the spots in which the spectra were acquired; scale bar: $0.2 \mathrm{~mm}$.

Under OM, most of the host rock is made up of antigorite and it is very rich in Fe-oxides (mainly magnetite). Extensional veins with chrysotile/antigorite filling contain relics of pyroxenes (diopside) with prismatic habit and kinked cleavages. Within the diopside grains, small veins filled with fibrous talc were developed.

Therefore, all the three serpentine polymorphs occur in the sample. Although the in situ composition and speciation could be determined using $\mu$-Raman, OM (Figure $3 a$ ) and SEM (Figure 3b,c), their habit could not be elucidated. The fiber morphology was better understood along fractures, discontinuities and close to the vein.

TEM investigations showed the four structural varieties of the serpentine group: chrysotile, lizardite, antigorite (both in platelets and fibers) and polygonal serpentine. Chrysotile consists of bundles of long and flexible fibrils with a hair-like appearance (Figure 3d). The chrysotile fibers are often curved and their length could be longer than $2 \mu \mathrm{m}$. TEM observations of single fibers showed cylindrical and rarely conical morphologies (Supplementary Materials Figure S1). The central empty 
core lies along the entire fibers length, sometimes with some interruptions (Supplementary Materials Figure S1), with outer and inner diameters of about 40 and $8 \mathrm{~nm}$, respectively. In some fibers the outer walls of the chrysotile are very thin while the core is wide. In rare occasions, chrysotile grew with a proto-chrysotile morphology (Supplementary Materials Figure S1) [32]. The proto-chrysotile morphology is the precursor of the cylindrical morphology of chrysotile $[18,33]$. The polygonal serpentine fibers often have a diameter greater than $100 \mathrm{~nm}$ (Supplementary Materials Figure S1) as measured in the (100) cross-section. All of the other minerals mostly have a platy morphology and thus are identified as non-fibrous (e.g., lizardite, antigorite). The fibrous antigorite was rarely detected. In recent years, fibrous antigorite has been identified worldwide in some outcrops of serpentinite $[17,18,34,35]$. The bundle sides have a smooth and nearly constant diameter along the length.

Concerning the SR X-ray $\mu \mathrm{CT}$ investigation, it was not possible to proceed to the volume rendering of this sample due to the occurrence of Fe-oxides such as magnetite, where the high density absorbed most of the radiation, obscuring the other phases.

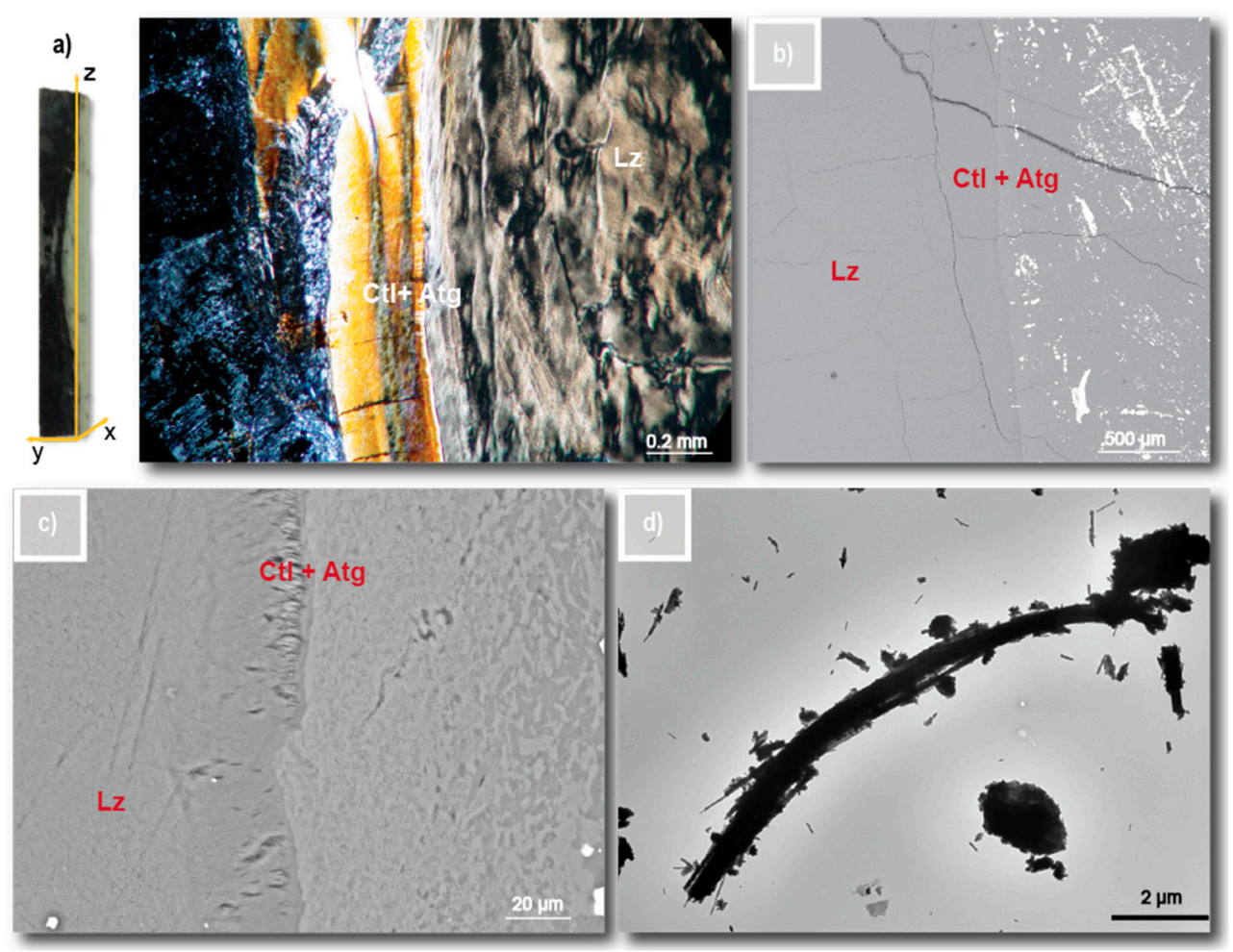

Figure 3. Sample 1 (S1). (a) Sample cut for tomographic scanning and photomicrography of the contact between the serpentinized peridotite and the lizardite vein; crossed polars. (b) SEM microphotograph (100× magnification) of serpentinized peridotite. (c) SEM microphotograph detail (2000× magnification) of the contact between the serpentinized peridotite and the lizardite vein (HV: $20 \mathrm{kV}$; Detector: Back-Scattered Electrons, BSE). (d) TEM image of a bundle of chrysotile fibers. Mineral name abbreviations are according to [36]. Atg: antigorite; Ctl: chrysotile; Lz: lizardite.

\subsubsection{Sample S2: Serpentinite with Tremolite Vein}

This sample mostly consists of a vein within serpentinite. The vein mainly constitutes dolomite and calcite (20 volume\%), clinochlore, Fe-oxides (10 volume\% with a grain size from 0.05 up to $1.2 \mathrm{~mm}$ ) and tremolite (the rest of the sample). In addition, the sample is very rich in mega-crystals of chrysotile/fibrous antigorite affected by kink deformation. Tremolite, very variable in shape and size, is often associated with diopside in variable amounts along the vein cross-section. The grain size of tremolite is variable, from very fine $(0.03 \mathrm{~mm}$ in length) up to a few millimeters in length. In addition, 
there are porphyroblasts that reach up to $4 \mathrm{~mm}$ in length. Moreover, the morphology of this phase becomes more fibrous due to the high aspect ratio of the particles. Tremolite occurs in an apparently prismatic/acicular habit with crystalline termination and well-defined edges or corners (Figure 4a); an asbestiform morphology is evidenced only close to voids (Figure $4 b, c)$.

The apparent fibrous morphology at lower magnifications was sometimes confirmed, resulting from bladed grains similar to veritable asbestos fibers (Figure 4d). In fact, under TEM, tremolite shows the classical strain-shaped morphology with parallel sides and regular termination (Supplementary Materials Figure S2), while sometime the longitudinal splitting of the fibers parallel to (110) cleavage surfaces into thinner fibrils is observed (Supplementary Materials Figure S2). The fibers length is generally $>6 \mu \mathrm{m}$ with a width of $<0.2 \mu \mathrm{m}$. We excluded the possibility of these being cleavage fragments of bladed prismatic tremolite because in that case the crystals would have shown irregular sides and blunt edges; as a rule, the cleavage fragments produced from the prismatic habits of the non-fibrous analogues of asbestos minerals are not veritable mineralogical fibers [37]. However, in the same samples cleavage fragments of tremolite were also detected (Supplementary Materials Figure S2). Antigorite and lizardite were also detected, although fibrous antigorite was always found in a low amount.

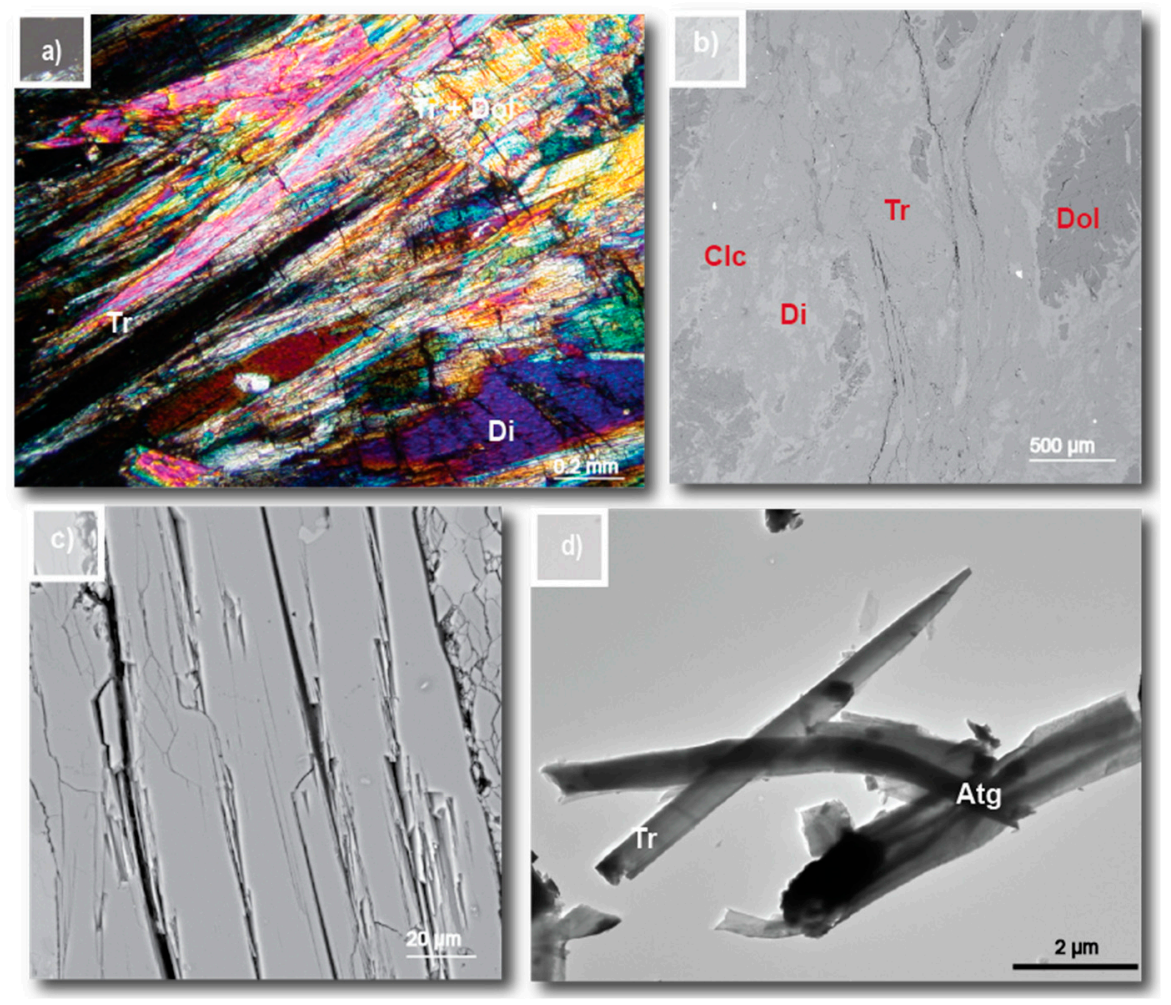

Figure 4. Sample 2 (S2). (a) Photomicrograph of the tremolite vein in the serpentinite; crossed polars. (b) SEM image $(100 \times$ magnification) of the vein of the serpentinite. (c) SEM image detail (2000× magnification) of the acicular/fibrous tremolite (HV: $20 \mathrm{kV}$; Det: BSE). (d) TEM image of tremolite + fibrous antigorite. Mineral name abbreviations are according to [36]. Atg: antigorite; Clc: clinochlore; Di: diopside; Do: dolomite; Tr: tremolite.

Moreover, sample S2 was cut for tomographic scanning (Figure 5a). Starting from single slices of tomography (Figure 5b), this technique could obtain images of the 3D arrangement and the geometric relationship between the fiber-bearing and the massive sectors of the studied rock (Figure 5c).

In particular, by focusing on the 3D rendering (Figure 5c), a diopside- and tremolite-rich vein was evidenced, in which the tremolite fibers are stretched (dashes); around there, dolomite and clinochlore 
are in contact. Under SEM it was not possible to clearly correlate such an arrangement on the polished section, complementary to the phase.

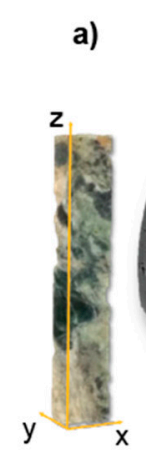

b)

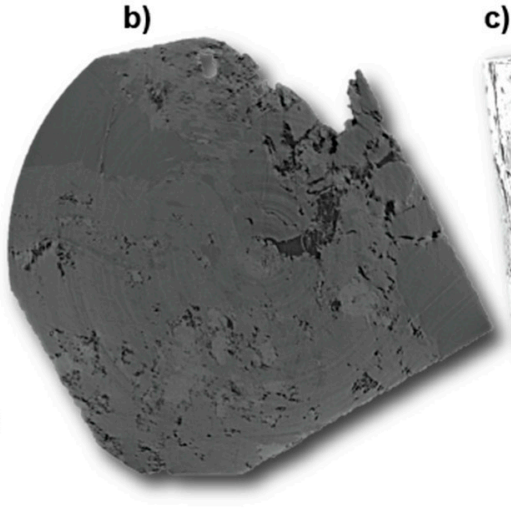

c)

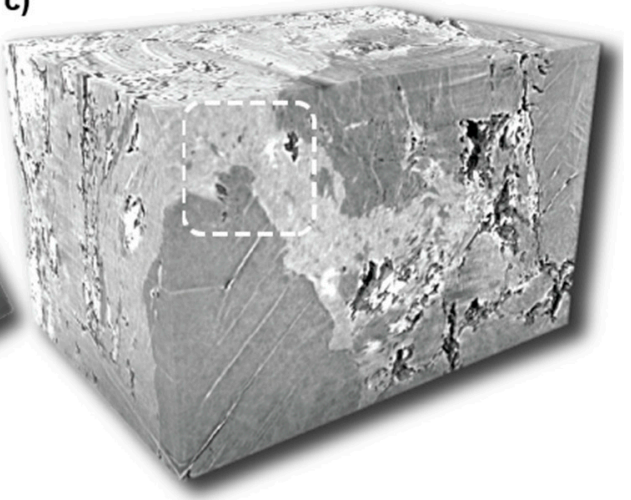

Figure 5. Sample 2 (S2). (a) Sample cut for tomographic scanning; (b) example of one single slice generated (1800 scans in total); (c) volume rendering $\left(7.7 \mathrm{~mm}^{3}\right.$ ) obtained by synchrotron radiation X-ray microtomography (rendering performed using the commercial software VGStudio Max 2.0 (Volume Graphics, Heidelberg, Germany)).

\subsubsection{Sample S3: Metabasalt with Plagiogranite Vein}

This sample is a metabasalt with ophitic texture cut by a plagiogranite vein. Quartz, albite, and secondary calcite are the vein filling phases. Acicular or fibrous actinolite varieties occur either at the point of contact with the vein or are scattered in the basalt groundmass, which is rich in skeletal plagioclases and acicular actinolite. Titanite is the most common accessory mineral phase.

Amphiboles, sometimes as fibril bundles, are generally included in plagioclase. The very fine grain size inhibits the ability to determine by SEM whether the amphiboles are made of fibrils or cleavage fragments of prismatic amphiboles. Acicular and very elongated actinolite crystals occur at the contact between metabasalt and the plagiogranite vein (Figure 6a). The acicular morphology tends to thin out at the tips, which are often needle-like, with a generally moderate aspect ratio (10:1). Sometimes fibrils and acicular crystals coexist (Figure 6b,c) in a tight envelope, as is particular evident in 3D images (Figure 7).

TEM investigations showed amphibole fibers with a ragged surface and irregular sides, typical of the cleavage fragment origin (Figure 6d; Supplementary Materials Figure S3). According to the crystals/chemical data obtained by EDS/TEM, the elongated particles of amphiboles were classified as actinolite, since they had a value of Si ranging from 7.90 to 7.99 atoms per formula unit (a.p.f.u.) and a $\mathrm{Mg} /\left(\mathrm{Mg}+\mathrm{Fe}^{2+}\right)$ value $>0.9$ a.p.f.u. [38]. Furthermore, low concentrations of very short chrysotile fibers were also identified (Supplementary Materials Figure S3).

In the sample slice (Figure $7 \mathrm{~b}$ ), the actinolite overgrows the plagiogranite and the plagioclase inside the metabasalt. The $3 \mathrm{D}$ reconstruction reveals the texture and the rugged contact between the metabasalt and the plagiogranite (Figure 7c). 

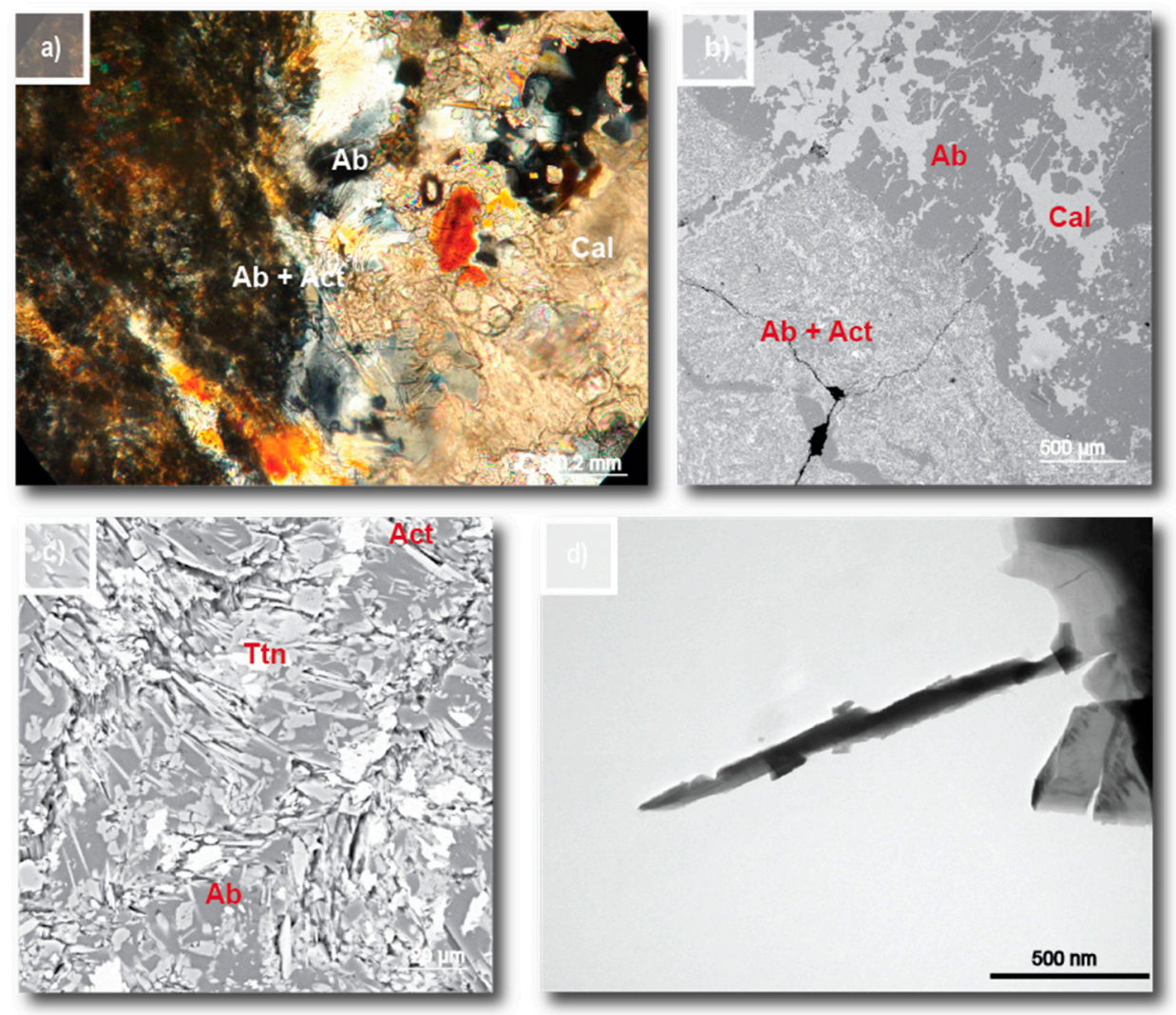

Figure 6. Sample 3 (S3). (a) Photomicrograph of the metabasalt and plagiogranite vein; crossed polars. (b) SEM image (100× magnification) of the metabasalt and plagiogranite vein. (c) SEM image (2000 $\times$ magnification) detail of the acicular actinolite (HV: $20 \mathrm{kV}$; Det: BSE). (d) TEM image of acicular actinolite. Mineral name abbreviations are according to [36]. Ab: albite; Act: actinolite; Cal: calcite; Ttn: titanite.
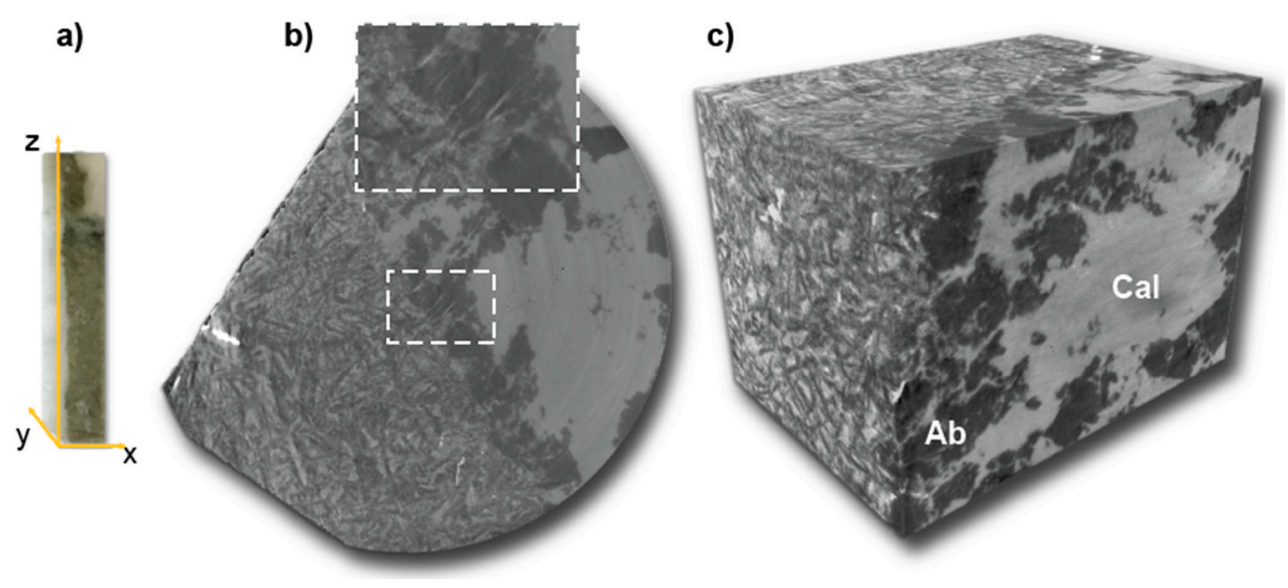

Figure 7. Sample 3 (S3). (a) Sample cut for tomographic scanning; (b) example of one single slice generated (1800 scans in total); (c) volume rendering $\left(7.5 \mathrm{~mm}^{3}\right)$ obtained by synchrotron radiation microtomography (rendering performed using the commercial software VGStudio Max 2.0). Mineral name abbreviations are according to [36]. Ab: albite; Cal: calcite.

\subsubsection{Sample S4: Pyroxenite}

This sample is a recrystallized cumulus rock and is mainly composed of granular clinopyroxene (diopside, $\sim 80$ volume $\%$ ) with a mosaic texture as the orthocumulus phase, subhedral richterite $(5-10$ volume $\%)$ as an inter-cumulus phase and local cataclastic, rare orthopyroxene (3 volume\%), 
tremolite (2 volume\%), interstitial mica (phlogopite), quartz and apatite as accessory minerals and finally trace spinel (overall $\sim 5$ volume $\%$ ).

The diopside is cut by talc micro-veins, and sometimes associated with titanite, ilmenite and tremolite. Part of the sample is a large vein, filled with tremolite, talc, calcite and chrysotile/antigorite with a finer grain size than clinopyroxene. Both fibrous and acicular habits are present. The grain size of the cumulus part of the sample is characterized by clinopyroxene, which has a grain from 0.2 to $8.5 \mathrm{~mm}$, richterite from 0.05 to $1.5 \mathrm{~mm}$, orthopyroxene from $0.5 \mathrm{up}$ to $1.5 \mathrm{~mm}$ and oxides with an average grain size of $0.1 \mathrm{~mm}$. In the cataclastic band, tremolite has an average grain size from $0.04 \mathrm{~mm}$ up to $0.4 \mathrm{~mm}$ and richterite has an average grain size from 0.06 to $0.3 \mathrm{~mm}$, whereas the orthopyroxene is a fine-grained unresolvable aggregate.

Prismatic and fine-grained fibrous amphiboles of the tremolite/actinolite series are evidenced in Figure 8a. In the tremolite and talc vein, fibers tend to develop (Figure 8b,c) into a 3D network (Figure 9). The richterite sometimes shows a fibrous habit. Therefore, although the fibers are asbestiform, they are not regulated asbestos due to their mineral composition.

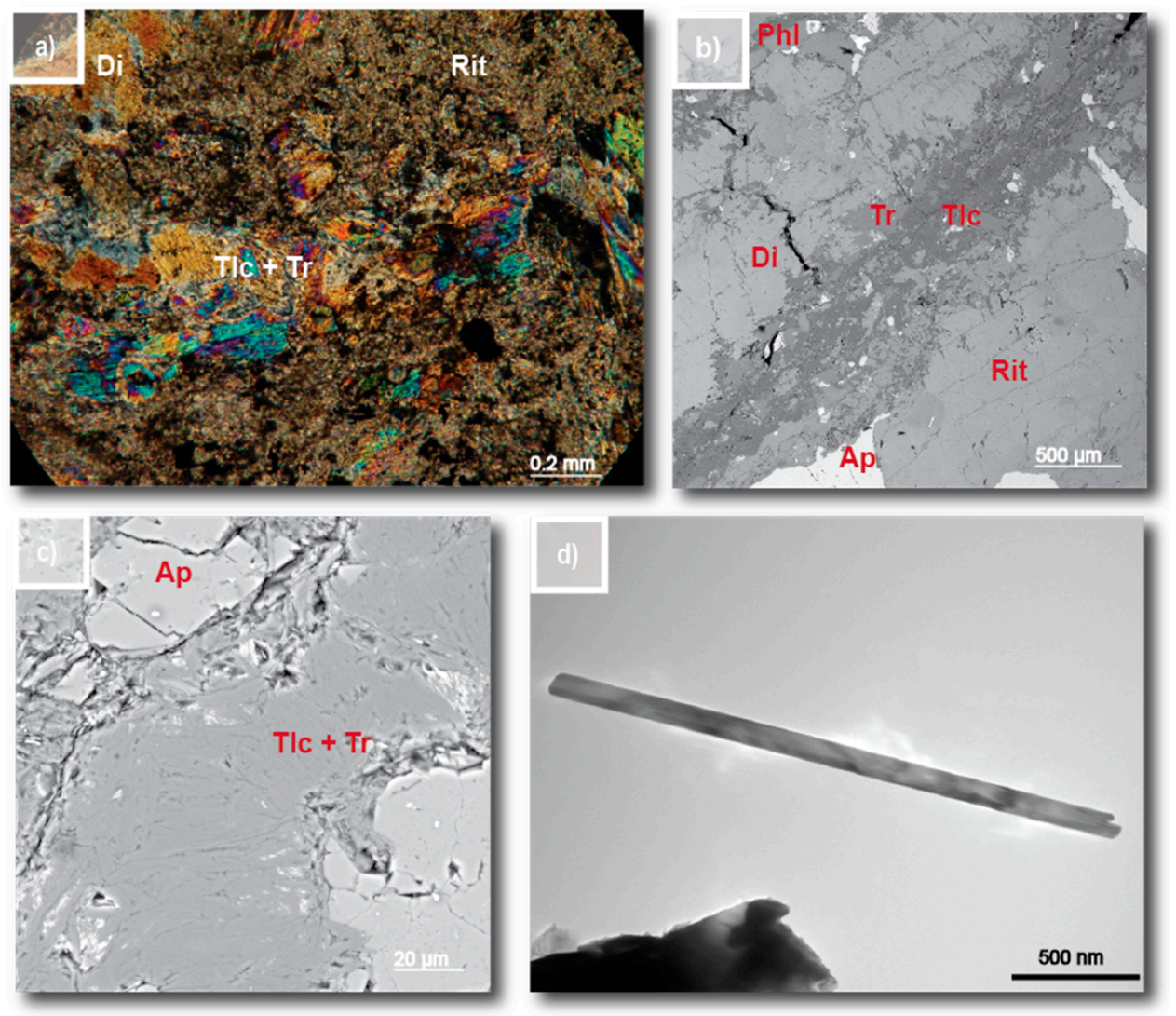

Figure 8. Sample 4 (S4). (a) Photomicrograph of the pyroxenite cut by a talc and tremolite vein; crossed polars. (b) SEM image (100× magnification) of pyroxenite cut by a talc and tremolite vein. (c) SEM image (2000× magnification) detail of the vein (HV: $20 \mathrm{kV}$; Det: BSE). (d) TEM image of fibrous actinolite. Mineral name abbreviations are according to [36] and references therein. Ap: apatite; Di: diopside; Phl: phlogopite; Rit: richterite; Tlc: talc; Tr: tremolite.

Fibers and elongated particles assemblage detected by TEM/EDS in the following samples were: asbestos actinolite, asbestos tremolite, cleavage fragment of tremolite and chrysotile. Asbestos actinolite exhibits a lath-shaped morphology (Figure 8d), as does asbestos tremolite (Supplementary Materials Figure S4). On the other hand, in the same samples, tremolite-classified as "non-asbestos" cleavage fragment-was observed (Supplementary Materials Figure S4). In fact, according to the literature data $[5,39]$ the asbestiform habit is confirmed by considering the typical square terminations of the 
fibrils, whereas the sample shown in Supplementary Materials Figure S4 better accounts for an origin in the cleavage along the $\mathrm{z}$ axis of the tremolite, as suggested by the oblique tip of the fiber and the projection of the polygonal cross-section of the double chain building. Chrysotile, rarely detected in this sample, showed a classic cylindrical shape.

The elaboration of the synchrotron data showed that the veins rich in talc and tremolite cut the sample. This was also evident from the low-magnification SEM image (Figure 8b), and from the vein direction and texture shown in both the 2D axial slice and 3D rendering (Figure 9a-c).

a)

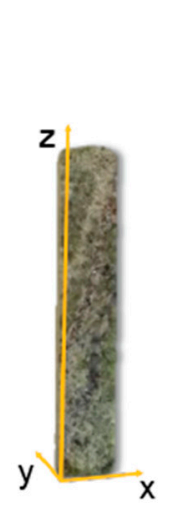

b)

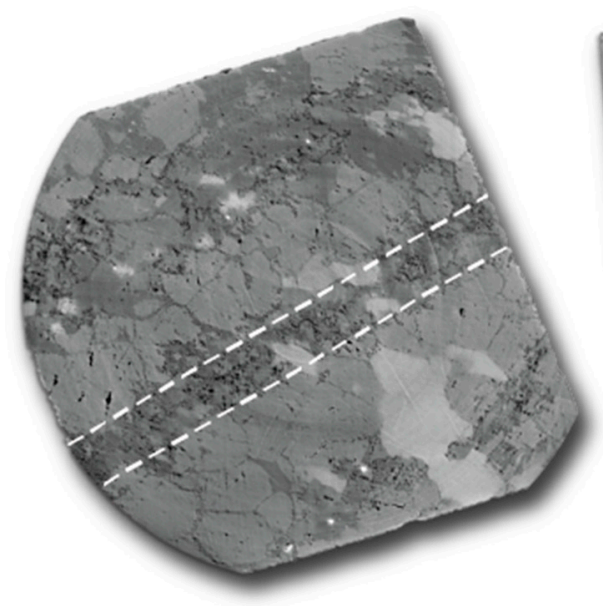

c)

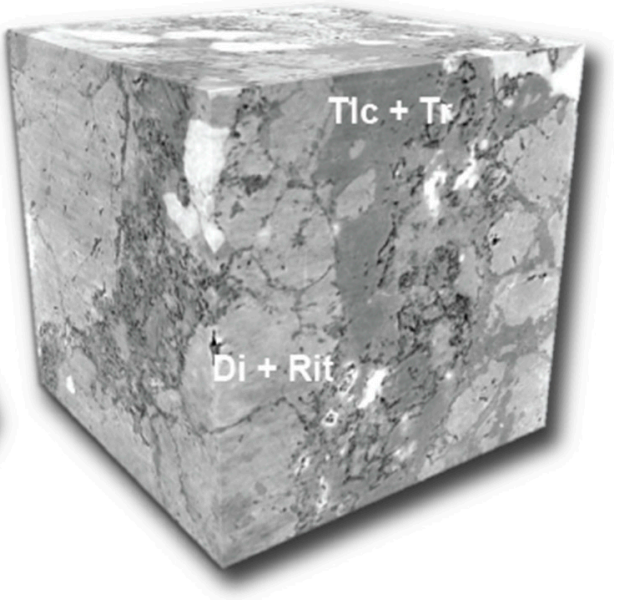

Figure 9. Sample 4 (S4). (a) Sample cut for tomographic scanning; (b) example of one single slice generated (1800 scans in total); (c) volume rendering $\left(7.4 \mathrm{~mm}^{3}\right.$ ) obtained by synchrotron radiation X-ray microtomography (rendering performed using the commercial software VGStudio Max 2.0). Mineral name abbreviations are according to [36]. Di: diopside; Rit: richterite; Tlc: talc; Tr: tremolite.

\section{Discussion and Conclusions}

The observations under OM allowed us to investigate the textures and the spatial relations between the mineralogical phases. The identification of asbestos minerals is easy under OM, but even at higher magnifications a fibrous habit has the same geometric parameters of prismatic/acicular crystals. Under SEM it is better characterize the aspect ratios and the textural relations between the various phases-often the habit is detectable, but discrimination among the serpentine polymorphs when embedded in the host rock is impossible.

TEM observation permitted the high-resolution discrimination for EMP and an effective distinction between regulated and non-regulated asbestos minerals. Therefore, combining all the techniques, the analyzed samples were found to be mainly composed of chrysotile and fibrous antigorite (S1); acicular associated with less fibrous tremolite and rare chrysotile (S2); acicular to prismatic actinolite (S3); and acicular/fibrous amphiboles of the actinolite-tremolite series (S4).

Preliminary results provided by SR X-ray $\mu \mathrm{CT}$ results showed that the serpentinized peridotite with the lizardite vein did not provide effective information, as the presence of magnetite (high density) caused the adsorption of most of the radiation, obscuring the other phases. Conversely, the other three samples exhibited good discrimination.

On the whole, synchrotron radiation X-ray microtomography is a technique that offers the possibility to observe and image the 3D morphology and the spatial relationship between the mineral phases that constituted the investigated samples. Furthermore, it is a semi-destructive technique which allows the analysis of samples under high magnification without grinding/milling and or the loss of their morphology. Nevertheless, it provides qualitative and volumetric but not quantitative information of the mineralogical phases; therefore, it proved a complementary technique to other 
conventional ones, useful to implement the research, but not exactly an effective activity for quantitative data restitution according to the legislative protocols in force for environmental monitoring [40,41].

It is noteworthy that none of the mentioned instruments (Table 1) is individually suitable for the unique and time-efficient identification of asbestos and non-asbestiform but still fibrous phases, particularly if these phases occur within massive rocks and are therefore not isolated.

Table 1. Summary of asbestos minerals and their fibrous but non-asbestiform analogues with their relative morphologies identified with the different analytical techniques used, respectively: Optical Microscopy (OM); Scanning Electron Microscopy combined with Energy Dispersive Spectrometry (SEM/EDS); Transmission Electron Microscopy combined with Energy Dispersive Spectrometry (TEM/EDS); Micro-Raman spectroscopy ( $\mu$-Raman); Synchrotron Radiation X-ray Microtomography $(\mathrm{SR}-\mu \mathrm{CT})$. Mineral name abbreviations are according to [36].

\begin{tabular}{|c|c|c|c|c|c|c|}
\hline Sample & Lithotype & OM & SEM/EDS & TEM/EDS & $\mu$-Raman & $\mathrm{SR}-\mu \mathrm{CT}$ \\
\hline S1 & $\begin{array}{l}\text { serpentinized } \\
\text { peridotite }\end{array}$ & serpentine polymorphs & $\begin{array}{l}\text { serpentine } \\
\text { polymorphs }\end{array}$ & $\mathrm{ctl}+\mathrm{lz}+$ platy and fibrous atg & $\mathrm{ctl}+\mathrm{atg}+\mathrm{lz}$ & - \\
\hline S2 & $\begin{array}{l}\text { serpentinite with } \\
\text { tremolite vein }\end{array}$ & $\begin{array}{c}\text { prismatic/acicular } \operatorname{tr}+ \\
\text { serpentine polymorphs }\end{array}$ & $\begin{array}{l}\text { acicular/fibrous tr } \\
+ \text { serpentine } \\
\text { polymorphs }\end{array}$ & $\begin{array}{c}\operatorname{tr} \text { (cleavage fragment and } \\
\text { fibrous), platy and fibrous atg }+ \\
\mathrm{lz}\end{array}$ & - & $\begin{array}{l}\text { fibrous } \mathrm{tr}+\text { di vein } \\
(\sim 1,7 \mathrm{~mm} \text { lengths })\end{array}$ \\
\hline S3 & $\begin{array}{l}\text { metabasalt with } \\
\text { plagiogranite vein }\end{array}$ & acicular/fibrous act & $\begin{array}{l}\text { cleavage } \\
\text { fragments and } \\
\text { fibrous act }\end{array}$ & cleavage fragments of act $+\mathrm{ctl}$ & - & $\begin{array}{l}\text { acicular act }(\sim 0, \\
117 \mathrm{~mm} \text { length })\end{array}$ \\
\hline S4 & pyroxenite & $\begin{array}{c}\text { prismatic/fibrous tr-act } \\
\text { series }\end{array}$ & $\begin{array}{l}\text { prismatic/fibrous } \\
\text { tr-act series }\end{array}$ & $\begin{array}{l}\text { fibrous act + cleavage } \\
\text { fragments/fibrous } t r+c t l\end{array}$ & - & $\begin{array}{l}\operatorname{tr}+\text { tlc vein }(\sim 0,75 \\
\text { mm lengths })\end{array}$ \\
\hline
\end{tabular}

If a complete, unique and comprehensive knowledge of asbestos-bearing rock is needed, it is important to plan and carry out a multi-analytical approach that takes into consideration the several aspects related to NOA occurrences within the various lithotypes.

Supplementary Materials: The following are available online at http://www.mdpi.com/2079-6439/7/5/42/s1, Figure S1. TEM images of: (a) a thin cylindrical chrysotile; (b) conical chrysotile with no-interrupted empty core; (c) poorly shaped proto-chrysotile indicated by black arrow; (d) cross-section of (100) polygonal serpentine. Figure S2. (a) TEM images of: tremolite asbestos as viewed perpendicular to the fiber axis; (b) flattened tremolite splitting longitudinally into thinner fibrils; (c) prismatic single crystals of tremolite (cleavage fragment). Figure S3. TEM image of single crystals of tremolite (cleavage fragment); note the irregular sides. Figure S4. (a) TEM images of: tremolite asbestos as viewed perpendicular to the fiber axis; (b) prismatic single crystals of tremolite (cleavage fragment); note the irregular sides. The wider end displays an initial split into two to three fibrils.

Author Contributions: Conceptualization, G.M.M. and L.G.; methodology, G.M.M., A.B. and G.L.; software, G.L.; validation, L.G., R.P. and A.B.; investigation, G.M.M., A.B., L.G., R.P. and G.L; resources, L.G. and R.P.; data curation, G.M.M.; writing —original draft preparation, G.M.M., L.G. and A.B.; writing—review and editing, G.M.M., A.B., L.G., R.P. and G.L.; supervision, L.G., R.P. and A.B.; funding acquisition, L.G., R.P. and A.B.

Funding: This research profited from the financial support of the "Analisi delle proprietà microstrutturali, chimico-fisiche di materiali inorganici; determinazioni quantitative della composizione mineralogica di materiali naturali e delle proprietà tecniche dei materiali litici" laboratory funds, DISTAV, University of Genoa, Italy. Moreover, part of this research was carried out with the financial support of "Piano Triennale della Ricerca (2017-2020) and later" (Deptartment of Biological, Geological and Environmental Sciences of the University of Catania, Italy.); scientific responsible: Rosalda Punturo. The work received financial support from the FFABR fund (by the Italian MIUR); scientific responsible: Andrea Bloise. Funding also came from the ELETTRA synchrotron laboratory (Trieste, Italy).

Acknowledgments: We gratefully acknowledge Elisa Sanguineti and Adrián Yus González for the support during the observation of the samples by SEM. We thank Nicola Campomenosi for help in acquisition and Simona Scrivano for the elaboration of the micro-Raman spectra. We thank Lucia Mancini, who was responsible for the SYRMEP beamline of the ELETTRA synchrotron laboratory (Trieste, Italy).

Conflicts of Interest: The authors declare no conflict of interest. 


\section{References}

1. Italian Ministerial Decree No. 06/09/1994. All. 2B. Determinazione Quantitativa Delle Concentrazioni di Fibre di Amianto Aerodisperse in Ambienti Indoor Mediante Microscopia Elettronica a Scansione. Available online: http://www.earaonline.eu/wp-content/uploads/Decreto-Ministeriale-06-09-94.pdf (accessed on 1 April 2019).

2. Belardi, G.; Vignaroli, G.; Trapasso, F.; Pacella, A.; Passeri, D. Detecting asbestos fibres and cleavage fragments produced after mechanical tests on ophiolite rocks: clues for the asbestos hazard evaluation. J. Mediterr. Earth Sci. 2018, 10. Available online: http://jmes.it/index.php/jmes/article/view/111 (accessed on 1 April 2019).

3. Gualtieri, A.F. (Ed.) Introduction. In Mineral Fibres: Crystal Chemistry, Chemical-Physical Properties, Biological Interaction and Toxicity; European Mineralogical Union: London, UK, 2017; Volume 18, pp. 1-15.

4. Baumann, F.; Ambrosi, J.-P.; Carbone, M. Asbestos is not just asbestos: An unrecognised health hazard. Lancet Oncol. 2013, 14, 576-578. [CrossRef]

5. Belluso, E.; Cavallo, A.; Halterman, D. Crystal habit of mineral fibres. In Mineral Fibres: Crystal Chemistry, Chemical-Physical Properties, Biological Interaction and Toxicity; Gualtieri, A.F., Ed.; Mineralogical Society of Great Britain and Ireland, 2017; Volume 18, pp. 65-109. Available online: https://www.minersoc.org/emu-not es-18.html (accessed on 1 April 2019).

6. Ballirano, P.; Pacella, A.; Bloise, A.; Giordani, M.; Mattioli, M. Thermal Stability of Woolly Erionite-K and Considerations about the Heat-Induced Behaviour of the Erionite Group. Minerals 2018, 8, 28. [CrossRef]

7. Cardile, V.; Lombardo, L.; Belluso, E.; Panico, A.; Capella, S.; Balazy, M. Toxicity and carcinogenicity mechanisms of fibrous antigorite. Int. J. Environ. Res. Public Health 2007, 4, 1-9. [CrossRef]

8. Petriglieri, J.R.; Laporte-Magoni, C.; Salvioli-Mariani, E.; Gunkel-Grillon, P.; Tribaudino, M.; Bersani, D.; Lottici, P.P.; Mantovani, L.; Bursi Gandolfi, N. Fibrous minerals in New Caledonia: A comparison of different analytical strategies for environmental monitoring. Conference Paper: Congresso Congiunto SIMP-AIV-SoGeI-SGI. Geosciences: A Tool in a Changing World, Pisa, Italy, 3-6 September 2017; Available online: https://www.socgeol.it/files/download/pubblicazioni/Abstract\%20Book/abstract_book_pisa_2017_ doi.pdf (accessed on 1 April 2019).

9. Bloise, A.; Punturo, R.; Catalano, M.; Miriello, D.; Cirrincione, R. Naturally occurring asbestos (NOA) in rock and soil and relation with human activities: the monitoring example of selected sites in Calabria (southern Italy). Ital. J. Geosci. 2016, 135, 268-279. [CrossRef]

10. Bloise, A.; Belluso, E.; Critelli, T.; Catalano, M.; Apollaro, C.; Miriello, D.; Barrese, E. Amphibole asbestos and other fibrous minerals in the meta-basalt of the Gimigliano-Mount Reventino Unit (Calabria, south-Italy). Rend. Online Soc. Geol. It. 2012, 21, 847-848.

11. Harris, K.E.; Bunker, K.L.; Strohmeier, B.R.; Hoch, R.; Lee, R.J. Discovering the true morphology of amphibole minerals: complimentary TEM and FESEM characterization of particles in mixed mineral dust: In Modern Research and Educational Topics in Microscopy. Modern Res. Educ. Top. Microsc. 2007, 3, 643-650.

12. Punturo, R.; Cirrincione, R.; Pappalardo, G.; Mineo, S.; Fazio, E.; Bloise, A. Preliminary laboratory characterization of serpentinite rocks from Calabria (southern Italy) employed as stone material. J. Mediterr. Earth Sci. 2018, 10. [CrossRef]

13. Punturo, R.; Bloise, A.; Critelli, T.; Catalano, M.; Fazio, E.; Apollaro, C. Environmental natural implications related to asbestos occurrences in the ophiolites of the gimigliano-mount reventino unit (Calabria, southern Italy). Int. J. Environ. Res. 2015, 9, 405-418.

14. Gaggero, L.; Crispini, L.; Marescotti, P.; Malatesta, C. Solimano, 4-6 December. Structural and microstructural control on chrysotile distribution in serpentinites from eastern ligurian ophiolites. In European Conference on Asbestos Risks and Management; Rome, 2006; pp. 134-139. Available online: https://www.researchgate.net/profile/Pietro_Marescotti/publication/236862917_Structural_and_microstru ctural_control_on_chrysotile_distribution_in_serpentinites_from_eastern_ligurian_ophiolites/links/0c9605 19a489cde671000000/Structural-and-microstructural-control-on-chrysotile-distribution-in-serpentinites-fr om-eastern-ligurian-ophiolites.pdf (accessed on 1 April 2019).

15. National Institute for Occupational Safety and Health (NIOSH). Asbestos by TEM: 7402. issue 2. 15 August 1994. Available online: https://www.cdc.gov/niosh/docs/2003-154/pdfs/7402.pdf (accessed on 1 April 2019).

16. ASTM International, ASTM D7521-13, Standard Test Method for Determination of Asbestos in Soil, West Conshohocken, PA, 2013. Available online: https://standards.globalspec.com/std/10018512/astm-d7521 (accessed on 1 April 2019). 
17. Bloise, A.; Critelli, T.; Catalano, M.; Apollaro, C.; Miriello, D.; Croce, A.; Barrese, E.; Liberi, F.; Piluso, E.; Rinaudo, C.; et al. Asbestos and other fibrous minerals contained in the serpentinites of the Gimigliano-Mount Reventino unit (Calabria, S-Italy). Environ. Earth. Sci. 2014, 71, 3773-3786. [CrossRef]

18. Bloise, A.; Catalano, M.; Critelli, T.; Apollaro, C.; Miriello, D. Naturally occurring asbestos: Potential for human exposure, San Severino Lucano (Basilicata, Southern Italy). Environ. Earth Sci. 2017, 76, 648. [CrossRef]

19. Rinaudo, C.; Belluso, E.; Gastaldi, D. Assessment of the use of Raman spectroscopy for the determination of amphibole asbestos. Mineral. Mag. 2004, 68, 455-465. [CrossRef]

20. Bloise, A.; Miriello, D. Multi-Analytical Approach for Identifying Asbestos Minerals in Situ. Geoscience 2018, 8, 133. [CrossRef]

21. Viti, C. Serpentine minerals discrimination by thermal analysis. Am. Miner. 2010, 95, 631-638. [CrossRef]

22. Compagnoni, R.; Groppo, C. Gli amianti in Val di Susa e le rocce che li contengono. Rend. Soc. Geol. It. 2006, 3. Nuova Serie, 21-28, 11 ff., 3 tabb. Available online: https://www.socgeol.it/files/download/workshop/05\% 20VS\%20(21-28).pdf (accessed on 1 April 2019).

23. International Standardization Organization (ISO). ISO/DIS 22262-2, Bulk Materials, Part 2: Quantitative determination of Asbestos by Gravimetric and Microscopical Methods. 10.08.2009b. Available online: https://www.iso.org/standard/56773.html (accessed on 1 April 2019).

24. Cloetens, P.; Pateyron-Salome, M.; Buffière, J.Y.; Peix, G.; Baruchel, J.; Peyrin, F.; Schlenker, M. Observation of microstructure and damage in materials by phase sensitive radiography and tomography. J. App. Phys. 1997, 81. [CrossRef]

25. Maire, E.; Withers, P.J. Quantitative X-ray tomography. Int. Mat. Rev. 2014, 59, 1-43. [CrossRef]

26. Brun, F.; Massimi, L.; Fratini, M.; Dreossi, D.; Billé, F.; Accardo, A.; Pugliese, R.; Cedola, A. SYRMEP Tomo Project: a graphical user interface for customizing CT reconstruction workflows. Adv. Struct. Chem. Imaging 2017, 3. [CrossRef]

27. Brun, F.; Accardo, A.; Kourousias, G.; Dreossi, D.; Pugliese, R. Effective implementation of ring artifacts removal filters for synchrotron radiation microtomographic images. In Proceedings of the 8th International Symposium on Image and Signal Processing and Analysis (ISPA), Trieste, Italy, 4-6 September 2013; Ramponi, G., Lončarić, S., Carini, A., Egiazarian, K., Eds.; Available online: https://ieeexplore.ieee.org/docu ment/6703823 (accessed on 1 April 2019).

28. Paganin, D.; Mayo, S.C.; Gureyev, T.E.; Miller, P.R.; Wilkins, S.W. Simultaneous phase and amplitude extraction from a single defocused image of a homogeneous object. J. Microsc. 2002, 206, 33-40. [CrossRef]

29. Herman, G.T. Image Reconstruction from Projections: The Fundamentals of Computerized Tomography, 1st ed.; Academic Press: New York, NY, USA, 1980; Available online: https://www.springer.com/us/book/978185233 6172 (accessed on 1 April 2019).

30. Groppo, C.; Rinaudo, C.; Cairo, S.; Gastaldi, D.; Compagnoni, R. Micro-Raman spectroscopy for a quick and reliable identification of serpentine minerals from ultramafics. Eur. J. Miner. 2006, 18, 319-329. [CrossRef]

31. Petriglieri, J.R.; Salvioli-Mariani, E.; Mantovani, L.; Tribaudino, M.; Lottici, P.P.; Laporte-Magoni, C.; Bersani, D. Micro-Raman mapping of the polymorphs of serpentine. J. Raman Spettrosc. 2015, 46, 953-958. [CrossRef]

32. Bloise, A.; Kusiorowski, R.; Lassinantti Gualtieri, M.; Gualtieri, A.F. Thermal behavior of mineral fibers. In Mineral Fibers: Crystal Chemistry, Chemical-Physical Properties, Biological Interaction and Toxicity; Gualtier, A.F., Ed.; European Mineralogical Union: London, UK, 2017; Volume 18, pp. 215-252.

33. Yada, K.; Lishi, K. Growth and Microstructure of Synthetic Chrysotile. Am. Miner. 1977, 62, 958-965.

34. Belluso, E.; Compagnoni, R.; Ferraris, G. Occurrence of Asbestiform Minerals in the Serpentinites of the Piemonte Zone, Western Alps. 1995. Available online: https://iris.unito.it/handle/2318/23533\#.XMxmpGixXIU (accessed on 1 April 2019).

35. Dogan, M.; Emri, S. Environmental health problems related to mineral dusts in Ankara and Eskisehir, Turkey. Yerbilimleri 2000, 22, 149-161.

36. Whitney, D.L.; Evans, B.W. Abbreviations for Names of Rock-Forming Minerals. Am. Miner. 2010, 95, 185-187. [CrossRef]

37. National Institute for Occupational Safety and Health (NIOSH). Asbestos Fibers and other Elongate Mineral Particles: State of the Science and Roadmap for Research. Curr. Intell. Bull. 2011, 62. Available online: https://www.cdc.gov/niosh/docs/2011-159/pdfs/2011-159.pdf (accessed on 1 April 2019). 
38. Ballirano, P.; Bloise, A.; Gualtieri, A.F.; Lezzerini, M.; Pacella, A.; Perchiazzi, N.; Dogan, M.; Dogan, A.U. The Crystal Structure of Mineral Fibers. In Mineral Fibers: Crystal Chemistry, Chemical-Physical Properties, Biological Interaction and Toxicity; Gualtieri, A.F., Ed.; European Mineralogical Union: London, UK, 2017; Volume 18, pp. 17-53.

39. Van Orden, D.R.; Allison, K.A.; Lee, R.J. Differentiating Amphibole Asbestos from Non-Asbestos in a Complex Mineral Environment. Indoor Built Environ. 2008, 17, 58-68. [CrossRef]

40. Gaggero, L.; Sanguineti, E.; Yus González, A.; Militello, G.M.M.; Scuderi, A.; Parisi, G. Airborne asbestos fibres monitoring in tunnel excavation. J. Environ. Manag. 2017, 196, 583-593. [CrossRef]

41. Gaggero, L.; Crispini, L.; Isola, E.; Marescotti, P. Asbestos in natural and anthropic ophiolitic environments: A case study of geohazards related to the northern apennine ophiolites (Eastern Liguria, Italy). Ofioliti 2013, $31,29-40$.

(C) 2019 by the authors. Licensee MDPI, Basel, Switzerland. This article is an open access article distributed under the terms and conditions of the Creative Commons Attribution (CC BY) license (http://creativecommons.org/licenses/by/4.0/). 